\title{
Temperature sensing across species
}

\author{
David D. McKemy
}

Received: 10 October 2006 / Accepted: 1 December 2006 / Published online: 12 January 2007

(C) Springer-Verlag 2007

\begin{abstract}
The ability to detect changes in temperature is a fundamental sensory mechanism for every species and provides organisms with a detailed view of the environment. This review focuses on what is known of the neuronal and molecular substrates for thermosensation across species, focusing on the three robust model systems extensively used to study sensory signaling, the nematode Caenorhabditis elegans, the fruit fly Drosophila melanogaster, and the laboratory mouse. Nematodes migrate to thermal climes that are amenable to their survival, a behavior that is regulated primarily through a single sensory neuron. Additionally, nematodes "learn" to seek out this temperate zone based upon their prior experience, a robust model of learning and memory. Drosophila larvae also prefer select thermal zones that are optimal for growth and have also developed vigorous mechanisms to avoid unfavorable conditions. In mammals, the transduction mechanisms for thermosensation have been identified primarily due to the fact that naturally occurring plant products evoke distinct psychophysical sensation of temperature change. More remarkably, the elucidation of the molecular sensors in mammals, along with those in Drosophila, has demonstrated conservation in the molecular mediators of temperature sensation across diverse species.
\end{abstract}

Keywords Thermosensation $\cdot$ Nematode $\cdot$ Fruit fly $\cdot$ Mouse . TRP

D. D. McKemy $(\triangle)$

Neurobiology Section, Department of Biological Sciences,

School of Dentistry, University of Southern California,

925 West 34th Street,

Los Angeles, CA 90089, USA

e-mail: mckemy@usc.edu

\section{Introduction}

The perception of external and internal temperature is a vital sensory mechanism that has implications in cellular and metabolic homeostasis, avoidance, and survival. Changes in environmental temperature are typically detected by select sensory neurons that can be crudely categorized into two populations, those that detect innocuous temperatures and those that sense noxious and potentially damaging thermal stimuli. The former are essential for many behavioral aspects that allow organisms to find food, locate a habitable climate zone, and maintain body temperature. The latter respond to stimulus intensities considered painful (nociceptive) and are essential in avoidance behaviors that work to limit exposure to environmental conditions that are harmful to the organism. Remarkably, the structural and anatomical makeup of the two types of thermosensory neurons is consistent across species. For example, the peripheral nerve endings of nociceptive neurons in the nematode and in fruit fly larvae terminate in naked nerve endings that are not associated with a specialized sensory structure, similar to nociceptive free nerve endings in mammals. In addition to structural similarities, in many cases, the molecular entities that are responsible for the detection and transduction of thermal stimuli are similar across species.

\section{Nematode thermosensation}

The relative simplicity of the Caenorhabditis elegans nervous system has made it an attractive and useful model organism for the study of the cellular and molecular basis for sensory signaling. A total of 959 somatic cells make up an adult hermaphrodite C. elegans, of which 302 comprise 
the nervous system [1]. Despite this minimalism, $C$. elegans respond to complex environmental cues associated with the senses of smell, taste, and touch, all of which evoke stereotypical primary behavioral responses. More remarkably, nematodes also exhibit more multifaceted behaviors such as learning and memory [2]. For example, C. elegans display a strong preference for the cultivation temperature at which they are satiated, such that they migrate, or thermotax, towards this temperature when placed upon a thermal gradient [3]. Conversely, when deprived of food at a given temperature, they subsequently exhibit aversion to this temperature [4]. Therefore, the nematode has been extensively studied as a model system to genetically and molecularly tease out the substrates for thermosensation, in addition to neural plasticity and a relatively simplistic form of learning and memory.

Remarkably, a single sensory neuron, AFD, appears to mediate most aspects of temperature detection and normal thermotactic behavior [5]. The AFD is 1 of the 12 neurons that make up one of the bilaterally symmetrical pair of nematode sensory organs called the amphid sensilla, located near the tip of the nose. Amphid neurons detect an array of sensory stimuli in addition to temperature, including watersoluble and volatile attractants, pheromones, and chemical repellents [1]. The thermosensory necessity of AFD neurons was established when it was observed that animals are incapable of isothermal tracking to their cultivation temperature and display a preference for cold temperatures (a cryophilic response) when these cells are ablated with laser microbeams [5]. Electron microscopy reconstruction analyses of the nematode nervous system have shown that the interneuron AIY is the primary postsynaptic partner of AFD. AIY in turn makes a functional synapse with the interneuron AIZ and the major integrating interneuron RIA, which also receives synaptic input from AIZ [6]. When AIY and AIZ interneurons in animals are individually ablated, these animals are also deficient in isothermal tracking. However, AIY-ablated animals are cryophilic, whereas those lacking AIZ are thermophilic, preferring temperatures warmer than those at which they were cultivated. When both interneurons are ablated simultaneously, animals become so inactive on thermal gradients that an accurate phenotype is unattainable [5]. RIA-ablated animals are partially defective in thermotaxis, in addition to other sensory defects. Thus, a model for the neural circuitry controlling thermotaxis was proposed in which the AIY and AIZ interneurons integrate opposing drives from AFD and an, as of yet, unidentified sensory neuron, respectively (for review see [1]; Fig. 1). AFD activation of AIY drives animals towards warmer temperatures, relative to that at which they were cultivated, whereas AIZ activity induces them to seek out cooler temperatures.
Temperature

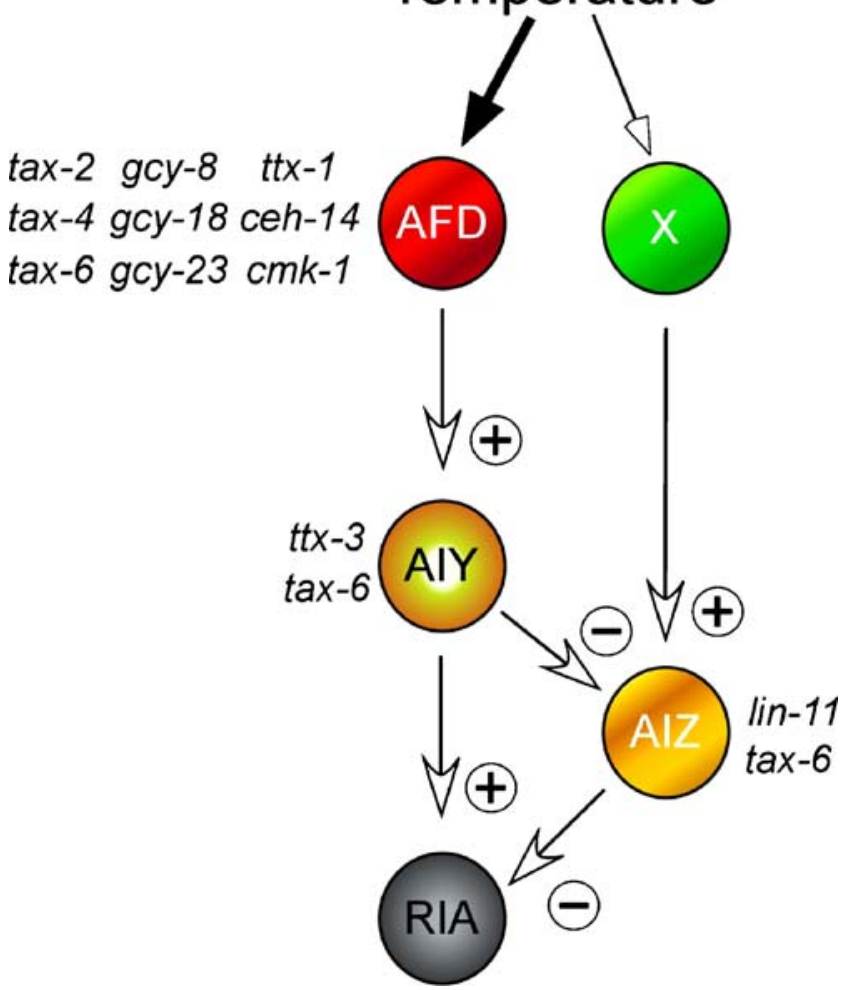

Fig. 1 The model for a $C$. elegans thermosensory neural circuit. Temperature-evoked activation of AFD stimulates the interneuron AIY, which in turn activates the integrating interneuron RIA. An unknown thermosensitive sensory neuron $(X)$ activates AIZ, which in turn inhibits RIA. However, AIZ activity is reduced by AIY activation in this model circuit. The identity of genes known to be expressed in, and regulate the function of, the neurons in this circuit are labeled. Modified from Mori and Ohshima [5]

How then does the AFD respond to temperature? Recent elegant approaches using the genetically encoded intracellular calcium sensor cameleon have begun to elucidate how temperature change alters AFD activity. Kimura et al. demonstrated that warming ramps above, but not below, the cultivation temperature evoke transient increases in intracellular $\mathrm{Ca}^{2+}$ in AFD neurons in vivo. This result suggests that the neurons are not responding to absolute temperature per se but to a step change in temperature from a set point established by the cultivation temperature [7]. Clark et al. [8] later showed that AFD responds dynamically to temperature in that $\mathrm{Ca}^{2+}$ responses are bidirectional and are able to phase-lock to oscillations in temperature. Furthermore, calcium responses have also been observed in the dendrites in vivo, and AFD activity is directly coupled with the postsynaptic AIY interneuron. Thus, many of the aspects associated with the behavioral responses of C. elegans to temperature change may be controlled by this single sensory neuron. 
Cyclic-nucleotide mediated transduction of thermal stimuli in AFD

What still remains a mystery is the actual temperature sensor in AFD neurons. Genetic studies suggest that thermal signals are transduced downstream of an unknown "thermosensor" in these neurons through a cGMP-gated ion channel encoded by the tax-2 and tax-4 genes [9, 10]. Mutants in both $\operatorname{tax}-2$ and tax-4 exhibit identical thermotactic deficits that are akin to those observed in AFDablated animals. The tax-4 and tax-2 genes encode $\alpha$ - and $\beta$-subunits, respectively, of a cGMP-gated ion channel that is most similar to those expressed in rod photoreceptors. In addition to AFD neurons, Tax- 2 and Tax- 4 proteins are also expressed in other sensory neurons including ASE, AWB, and AWC and are localized to cilia and dendritic structures of these neurons $[9,10]$. Mutants are also defective in many aspects of olfaction and chemosensation of salts, consistent with this neuronal localization. Interestingly, the behavioral phenotype of double mutants is not exaggerated in comparison to the single mutants, and expression of tax-4 is able to rescue the tax-2 mutant chemotactic phenotype [9]. However, the reciprocal is not true; expression of tax-2 does not ameliorate the tax-4 phenotype. Consistent with the results of the genetic rescue experiments, Tax-4 by itself forms a functional ion channel when expressed in HEK293 cells in vitro, whereas Tax- 2 does not $[10,11]$. Tax-4 is highly sensitive to cGMP versus cAMP $\left(K_{\mathrm{D}}\right.$ values of $4 \times$ $10^{-7}$ versus $1.4 \times 10^{-4} \mathrm{M}$, respectively [10]). When coexpressed, Tax-4 and Tax-2 form a functional heteromeric channel that is $\sim 25$-fold less sensitive to cGMP in comparison to Tax-4 alone but still retains selectivity for cGMP over cAMP [11]. Additionally, Tax-4/Tax-2 channels are highly $\mathrm{Ca}^{2+}$-permeable but much less sensitive to divalent ion block than Tax-4 channels. As described above, warming of animals above their cultivation temperature evokes an increase in intracellular $\mathrm{Ca}^{2+}$ in AFD, and this response is absent in a tax-4 null mutant [7]. Thus, thermosensory signaling in AFD neurons is likely mediated by increased intracellular cGMP that promotes fluctuations in cytosolic $\mathrm{Ca}^{2+}$ concentrations as a part of the signal transduction pathway. Thus, the cyclic nucleotide-gated channel encoded by the $\operatorname{tax}-2$ and $\operatorname{tax}-4$ genes is likely a transducer of multiple modalities of sensory stimuli determined by the cell-type expressing the channels.

How then is a change in external temperature transduced into increased cGMP in nematode AFD neurons? Some clues to this process came from a recent work by Inada et al. [12] who used a reverse genetics approach to identify three members of a subfamily of guanylyl cyclase genes, $g c y-8, g c y-18$, and gcy-23, important for thermotaxis. Transgenic reporter constructs for each gene are expressed exclusively in AFD neurons and are localized to nerve endings. Interestingly, abnormal thermotactic behaviors are only observed in animals with double or triple gene mutations and not in any of the single mutants. Moreover, the abnormal phenotype of the triple mutants could be rescued by the expression of just one guanylyl cyclase, suggesting that these enzymes are functionally redundant. However, the mechanism for how thermal stimuli are converted into guanylyl cyclase activity remains uncertain. Two possible pathways have been proposed, one requiring temperature-dependent activation of an, as of yet, unidentified G-protein-coupled seven transmembrane receptor upstream of these enzymes, or, alternatively, that the guanylyl cyclases themselves act as temperature sensors [12]. Further biochemical and in vitro tests may soon shed light on these possibilities.

Regulatory mechanisms of C. elegans thermosensation

Analyses of several additional mutant nematode strains have identified a number of genes that likely serve important regulatory roles in $C$. elegans thermosensation. Many of these appear to function in cell fate determination, gene expression, and regulation of the signal transduction pathway described above. Early screens of sensory mutants identified a number of defects that lead to altered thermotaxis and were referred to as $t t x$ mutations [3]. Of these, $t t x-1$ mutants fail to track isothermally when cultivated at $20^{\circ} \mathrm{C}$ and are strongly cryophilic $[3,13]$. AFD sensory nerve endings are severely defective in these mutants [14]. AFD neurons are distinguished by their elaborate microvillar finger-like structures that emanate from a single cilium $[6,14]$. However, these microvilli are completely lost in $t t x-1$ mutants, and the morphology of the cilia is grossly abnormal with its length approximately three times the norm [14], suggesting that Ttx-1 mediates the morphogenesis of AFD sensory nerve endings [13]. The $t t x-1$ gene encodes a homologue of the OTD/OTX family of homeodomain proteins that have been implicated in patterning and development of sensory structures in both invertebrates and vertebrates [15]. Expression of GFP reporters from the $t t x-1$ locus is exclusive to AFD neurons and is first observed after the establishment of cell fate and maintained throughout development. Interestingly, misexpression of $t t x-1$ in olfactory neurons is sufficient to confer an AFD-like phenotype to these neurons [13]. Thus, like other members of the OTD/OTX gene family, $t t x-1$ appears to mediate the development of the sensory nerve structure of AFD.

As the behavioral phenotype of ttx- 1 mutants is synonymous with that observed in AFD-ablated animals, 
a similar correlation has been made with $t$ tx- 3 mutants and animals in which the interneuron AIY is killed [5, 16]. Like $t t x-1$, the genetic basis for $t t x-3$ mutants appears to involve disrupted gene expression as $t t x-3$ encodes a LIM homeodomain protein, a class of highly conserved neural regulatory genes $[16,17]$. Consistent with the behavioral phenotype, Ttx-3 is expressed exclusively in adult AIY interneurons and is likely involved in regulating expression of genes required for AIY differentiation as excessive neurite outgrowth is observed in axonal projections. Similarly, another LIM homeobox gene, lin-11, is expressed in the opposing AIZ interneuron, and morphology of these cells is defective in lin-11 mutants with a phenotype remarkably similar to that observed in AIY interneurons in $t t x-3$ mutants [17]. The lin-11 mutants were first reported to be thermophilic, a phenotype that mimics that observed in AIZ-ablated animals [5, 17]. However, Satterlee et al. [13] subsequently found lin-11-null mutants to be only weakly thermophilic and suggested that lin-11 does not specify all thermoregulatory functions of AIZ interneurons. In this study, double mutants of $t t x-1, t t x-3$, and $l i n-11$ were examined and, consistent with their observations, ttx-1:lin11 and $t t x-1: t t x-3$ double mutants were mostly cryophilic. Lastly, a third LIM homeobox gene, ceh-14, is expressed in AFD neurons, and mutants in this transcription factor are largely athermotactic, a phenotype remarkably similar to AFD-ablated animals [18]. Only minor structural defects are observed in AFD neurons from ceh-14 mutants with many markers of these sensory cells still intact. Thus, when taken in context of the behavioral phenotype of these animals, these data suggest that ceh-14 does not play a role in the fate of AFD neurons but is required for differentiation [18].

In addition to transcriptional regulation of nematode thermosensation, post-translational modifications, such as phosphorylation, regulate thermotaxis and memory of cultivation temperature in C. elegans. Mutations in tax-4 and cmk-1, the latter coding for a $\mathrm{Ca}^{2+} /$ calmodulin-dependent protein kinase I (CaMKI), result in temperature-dependent defects in gene expression in AFD neurons, in addition to the thermotactic deficits already discussed in $\operatorname{tax}-4$ mutants [19]. Tax-4 appears to regulate AFD gene expression upstream of Cmk-1, and this enzyme functions in AFD neurons in a manner distinct from those previously described for this class of kinase [19]. Therefore, it was proposed that thermotactic behavior, including memory of cultivation temperature, occurs as a result of Tax-4- and Cmk-1-mediated gene expression. Similarly, mutations in the $\operatorname{tax}-6$ gene, which encodes for the $\mathrm{Ca}^{2+} /$ calmodulin-dependent phosphatase calcineurin A subunit, result in a number of sensory abnormalities, including impaired chemotaxis and thermotaxis $[3,20,21]$. Tax-6 is expressed in a number of tissues, including sensory neurons, interneurons, and muscle cells and, more specifically, in all three neurons of the putative thermosensory circuit, AFD, AIY, and AIZ. Phenotypically, tax- 6 mutants tend to migrate towards temperatures above that at which they were cultivated (thermophilic). When a tax-6 cDNA was specifically expressed in AFD neurons, via the $g c y-8$ promoter, in tax- 6 mutants, these animals showed normal thermotactic responses, thereby suggesting that calcineurin works cell-autonomously in AFD neurons [21]. However, AFD-specific expression of a constitutively active form of Tax-6 resulted in athermotactic or cryophilic behavior, as if the AFD neuron was inactive. In addition to AFD function, $\operatorname{tax}-6$ is also essential for thermal signaling in AIZ interneurons. Kuhara and Mori [22] recently monitored temperature-evoked changes in intracellular $\mathrm{Ca}^{2+}$ in $\mathrm{AIZ}$ interneurons and found that starvation down-regulated AIZ activity in wild type animals, a phenomenon not observed in tax-6 mutants. Taken together, these data support a model in which neuronal activity activates calcineurin, presumably through Tax-2/Tax-4 mediated $\mathrm{Ca}^{2+}$ entry, which in turn negatively regulates thermal signaling in a manner that is related to associative learning.

\section{Thermal nociception in C. elegans}

In stark contrast to the detailed descriptions of the neural circuitry and essential genes for nematode thermotaxis, little is known of the neural substrates involved in behavioral responses to noxious temperatures [23]. Other noxious modalities, such as mechanical and chemical, are primarily detected by the two ASH neurons located at the tip of the nose, but perturbation of ASH cell signaling has no affect on temperature responses [23]. Elegant behavioral analyses performed by Wittenburg and Baumeister [24] demonstrated that $C$. elegans are able to generate nocifensive, or pain-like, responses to temperatures above the range of fertile temperatures $\left(13\right.$ to $\left.26^{\circ} \mathrm{C}\right)$. Adult animals exhibit a stereotyped withdrawal response to temperatures near $33^{\circ} \mathrm{C}$ that manifests as a stop in forward movement, followed by reversing for one to two body lengths, then a reorientation away from the heat source. Ablation of AFD, AIY, or AIZ does not alter this response nor is this behavior altered in many of the known thermotactic mutants, such as tax-2, tax -4 , ttx- 1 , lin-11, unc-86, and ttx-3 [24]. Surprisingly, the pungent component of hot chili peppers capsaicin, which activates the mammalian thermosensor TRPV1 (see below) [25], sensitized withdrawal behaviors [24]. Capsaicin itself does not evoke an acute nocifensive response, but this effect is attenuated by the competitive capsaicin antagonist capsazepine $[24,26]$. The $C$. elegans genome contains several capsaicin receptor-related genes of which osm-9 and ocr-2 
are required for nociceptive responses mediated by the ASH nociceptor [23]. However, these related proteins do not appear to be receptors for capsaicin. Moreover, thermal avoidance behaviors are still intact in osm-9 mutants [23]. Thus, the cellular and molecular substrates mediating acute thermal avoidance in the nematode remain unclear.

\section{Drosophila thermosensation}

Many developmental and behavioral aspects of the fruit fly Drosophila melanogaster parallel those of higher organisms. Moreover, like the nematode $C$. elegans, a sophisticated array of genetic and molecular tools have been developed that makes analysis of gene function in this multi-cellular organism especially feasible. Drosophila have been used as a robust model system to gain insights into many of the cellular and molecular aspects of vision, gustation, and olfaction (for review see [27-29]). However, it has only recently been employed to elucidate the basis of thermosensation.

\section{Thermotactic and thermosensory behaviors in Drosophila}

Like C. elegans, Drosophila prefer to reside at specific temperatures. Sayeed and Benzer [30] found that when adult flies are placed upon a linear thermal gradient (18 to $31.5^{\circ} \mathrm{C}$ ), these animals show a strong preference for $\sim 24^{\circ}$ C. However, unlike nematodes, flies cultivated or acclimatized at temperatures either above or below $24^{\circ} \mathrm{C}\left(29\right.$ or $18^{\circ}$ C) still retain this partiality and thus do not reset their preferences based upon experience. Moreover, in a twotemperature choice paradigm, adult flies prefer 22 over $30^{\circ}$ C. Similarly, Liu et al. [31] showed that Drosophila larvae prefer to reside at $18^{\circ} \mathrm{C}$ when given the choice of this temperature versus either 11 or $30^{\circ} \mathrm{C}$. In another experimental paradigm, larvae placed upon a thermal gradient from 27 to $41^{\circ} \mathrm{C}$ were shown to thermotax to the coolest temperatures, avoiding those above their optimal growth temperature [32]. What about temperature extremes? As in many models of nociception in mammals, noxious heat evokes a stereotypical nocifensive-like response in Drosophila. Tracey et al. [33] developed a simplistic yet elegant paradigm to assess the behavioral response of Drosophila larvae to noxious heat. Similar to freely moving nematodes, Drosophila larvae will pause and move away when lightly touched with a probe set at ambient temperatures [34]. However, when the probe is heated to temperatures above $39^{\circ} \mathrm{C}$, this same touch stimulus will evoke a nocifensive response in which the larva vigorously roll away from the probe in a cork-screw like motion [33]. Thus, Drosophila possess innate and stereotypical behav- ioral responses to temperature and are able to thermotax to an environment that is suitable for survival.

Neuronal substrates for thermosensation

Like in the nematode, genetic or surgical ablation of specific types or subsets of neurons has identified those likely to be involved in Drosophila temperature sensation. In adult flies, Sayeed and Benzer [30] set out to establish the anatomical location of thermoreceptors responsible for temperature preference in their linear temperature gradient assays and found that if the third antennal segments are removed, flies no longer exhibit a thermal preference and distribute evenly across the gradient. Moreover, the Drosophila mutant $s s^{a}$, in which the distal regions of the third antennal segment are mutated into leg-like structures, exhibits no temperature preference when placed on the linear gradient or when presented with temperature steps $[30,35]$. However, both control and antennae-less flies avoid temperatures above $31^{\circ} \mathrm{C}$, leading the authors to suggest the existence of two "thermosensors," one in the fly antennae that mediates the preference for $24^{\circ} \mathrm{C}$ and a second that drives flies away from higher temperatures that may be perceived as noxious [30].

Whereas these seminal observations were conducted in adult flies, recent approaches to address the cellular and molecular basis for Drosophila thermosensation have used fly larvae, as this has been a more tractable model system. Like in C. elegans, peripheral sensory neurons in larvae have been mapped anatomically and structurally and can be observed optically as they lie at the surface of the semi-transparent cuticular layer [31]. Sensory neurons fall into two classes: type I, which terminates in a single ciliated dendrite, and type II, which lack sensory cilia and extend multiple dendrites [23]. In the adult, type I neurons are organized in complex structures, such as the sensory bristles that cover the fly and chordotonal organs, and function in various aspects of mechanosensation [36]. Type II neurons, on the other hand, spread their dendrites throughout the epidermis and terminate as free nerve endings, very much like vertebrate nociceptors [23, 37].

In larvae, distinct thermosensory responses have been observed in type I neurons in the terminal sensory organ and in type II multidendritic (md) neurons in the abdominal body wall $[31,33,35]$. Using transgenic larvae expressing the $\mathrm{Ca}^{2+}$ reporter cameleon, Liu et al. [31] observed increased intracellular $\mathrm{Ca}^{2+}$ in only the terminal organ upon cooling from 18 to $10^{\circ} \mathrm{C}$ but not when temperatures were raised to $40^{\circ} \mathrm{C}$. Extracellular electrical recordings in the terminal organ also uncovered substantial basal activity at room temperature, which increased with cooling and 
decreased when the larvae were warmed. In contrast, intracellular $\mathrm{Ca}^{2+}$ largely decreased in type II md neurons upon cooling, whereas heating produced a mixed result with some cells exhibiting increased intracellular $\mathrm{Ca}^{2+}$, whereas others had no changes at all [31]. Using suctionelectrode recordings from sectioned abdominal nerves, Tracey et al. [33] observed increased spiking at temperature thresholds of $\sim 28$ and $38^{\circ} \mathrm{C}$, suggesting the existence of at least two functionally distinct $\mathrm{md}$ thermoceptors in the abdominal wall.

Lastly, genetic silencing of either type I or type II neurons has demonstrated segregated behavioral responses between the two sensory neuron types. When synaptic transmission was blocked in the terminal organ by expression of the tetanus toxin light chain (TeTxLC), transgenic larvae no longer preferred 18 over $11^{\circ} \mathrm{C}$ [31]. However, the larvae still avoided warmer temperatures in that they preferred 18 to $30^{\circ} \mathrm{C}$ comparable to wild type larvae. Similarly, expression of TeTxLC in md neurons largely prevented the nocifensive rolling-escape behavior exhibited by wild type larvae when touched with a probe heated to $46^{\circ} \mathrm{C}$ [33]. Thus, these data suggest that type I neurons may in fact be cold sensors and mediate thermotactic responses that drive Drosophila larvae away from temperatures below $18^{\circ} \mathrm{C}$, whereas type II neurons detect noxious, tissue-damaging heat and trigger an escape response.

TRP ion channels mediate thermosensory responses

What then mediates the response to temperature in Drosophila? Remarkably, evidence to date suggests that members of the transient receptor potential (TRP) family of ion channels mediate thermosensation in the fly, demonstrating that there is a high degree of similarity between the molecular entities mediating thermosensation in mammals and insects (see below) [29]. This link was first observed in an elegant forward genetic screen conducted by Tracey et al. [33] in which they looked for mutations that prevent the nocifensive rolling response observed when larvae came in contact with a heated probe. A mutant, called painless, was isolated, which exhibits significantly reduced response to stimulation with a probe heated between 42 and $48^{\circ} \mathrm{C}$, although temperatures above $52^{\circ} \mathrm{C}$ still evoke a nocifensive response similar to that observed in wild types. This observation is intriguing in light of the fact that similar temperature ranges are observed for mammalian nociceptive afferents, with $\mathrm{C}$ - and type II $\mathrm{A} \delta$-fibers responding to a thermal threshold of $\sim 43^{\circ} \mathrm{C}$ and type I A $\delta$-fibers exhibiting activation above $52^{\circ} \mathrm{C}$ [37]. In addition to deficits in thermosensation, painless mutants are also less responsive to mechanical stimuli. Wild type larvae stimulated with a $45-\mathrm{mN}$ von Frey filament will also roll away from the stimulus, but this response is absent in painless mutants [33]. Higher threshold mechanical stimuli $(100 \mathrm{mN})$ will evoke a nocifensive response, suggesting that painless mediates both thermal and mechanical nociception to moderate intensity noxious stimuli.

The painless gene codes for a member of the TRPA subfamily and is expressed in a subset of multidendritic neurons. Transcripts are observed in md neuron precursors and localized to the dendrites in advanced embryos [33]. Consistent with mRNA expression, anti-Painless antisera and a transgenic strain that drives GFP expression from the painless promoter, observed expression in the chordotonal organs, multidendritic neurons, the antennal-maxillary complex, and a subset of cells in the central nervous system. Immunoreactivity was strongly localized to puncta in the dendritic arbor found beneath the embryonic epidermis. As described above, extracellular recordings of md neuronal activity demonstrated that heating above $38^{\circ} \mathrm{C}$ evokes an increase in spike frequency, which is absent in painless mutants [33]. Interestingly, a biphasic increase in activity is observed between 25 and $30^{\circ} \mathrm{C}$ in painless mutants but not in wild type recordings. However, recordings were not performed at the temperature extremes near $52^{\circ} \mathrm{C}$, stimulus intensities that evoke a nocifensive response from painless mutants. Thus, Painless expression in md neurons suggests that these sensory neurons may be akin to moderate heat threshold mammalian nociceptors [37].

Transgenic lines expressing reporter constructs from the painless locus also revealed expression in subsets of sensory neurons involved in gustation [38]. Expression in gustatory bristles in the labial palpus, leg tarsus, and the anterior wing margin was observed and, in many cases, overlapped with neurons expressing markers via the gustatory neuron reporter Gr66a, which have been implicated in aversive responses to tastants [38, 39]. The only TRPA channel in mammals is a receptor for many pungent compounds, including allyl isothiocyanate (AITC), the pungent ingredient in wasabi (see below) [40, 41]. In a two-choice preference test, wild type flies exhibit a strong aversion to AITC, whereas painless mutants do not [38]. This aversion was further shown to be gustatory. When ravenous flies encounter sweet substances, they extend their proboscis, a behavior that declines in the presence of aversive substances such as AITC. The painless mutants do not exhibit aversion to isothiocyanates in this assay, and the wild type phenotype is rescued by transgenic expression of a wild type painless cDNA, as is also the case in the twochoice preference assay [38]. This gustatory defect in painless mutants is not due to a general inhibition of gustation, as mutants still respond to other tastants such as quinine and $\mathrm{NaCl}$. Therefore, these genetic and behavioral data demonstrate that the Drosophila painless is likely the functional orthologue of the mammalian wasabi receptor 
TRPA1. However, this hypothesis needs to be solidified by a demonstration that isothiocyanates can directly activate Painless in heterologous expression systems, as is the case for the mammalian channel [40]. Similarly, genetic and behavioral evidence clearly shows that painless mediates thermosensory and mechanosensory signaling in vivo. However, it has yet to be shown experimentally that Painless is the primary "detector" of these stimulus modalities or if it is downstream of an unknown thermosensor or mechanosensor.

In addition to Painless, the Drosophila genome encodes three other members of the TRPA subfamily: dTRPA1, dTRPA2, and dTRPA3 [42]. Of these, dTRPA1 and dTRPA2, also known as Pyrexia, have been implicated in thermosensation $[32,43]$. dTRPA1 was first shown to be temperature sensitive in vitro, as threshold temperatures in the warm range $\left(\sim 27^{\circ} \mathrm{C}\right)$ activate transient ionic currents when the channel is expressed in heterologous systems [44]. Moreover, dTRPA1 is essential for larval thermotaxis, as knockdown of channel expression by RNAi prevents these animals from avoiding temperatures above the optimum [32]. This phenotype is specific for dTRPA1 as dsRNAs for the other TRPA family members, as well as the two Drosophila TRPV channels and the lone TRPM, have no affect on this phenotype. Whereas knockdown of dTRPA1 influences thermotactic behaviors, nocifensive responses like those absent in painless mutants are unaffected. Thus, dTRPA1 likely plays a role in Drosophila thermotaxis but is not required for avoidance and nocifensive responses to noxious heat. Antisera raised against dTRPA1 label primarily a small subset of central brain neurons, neuroendocrine cells of the corpus cardiacum, and unidentified cells adjacent to the mouthhooks and in the digestive system [32]. Surprisingly, protein expression is not observed in the two regions previously known to contain thermosensitive sensory neurons, multidendritic neurons, and the chordotonal organs [31, 33]. In larvae, in which md neurons were silenced by expression of TeTxLC, or in animals lacking chordotonal neurons, no deficits were observed in the thermotactic assay used (thermal gradient from 27 to $41^{\circ} \mathrm{C}$ ) [32]. However, when TeTxLC, or the cell death-promoting gene $\mathrm{Hid}$, is expressed under the putative dTRPA 1 promoter, larvae do not fully migrate to the cooler zone $\left(27^{\circ} \mathrm{C}\right)$, a partial phenotype of that exhibited after RNAi knockdown of dTRPA1. Thus, when taken as a whole, these data demonstrate that dTRPA1 mediates thermal avoidance of innocuous temperatures above the optimal growth temperature of Drosophila larvae and, moreover, unmasks a previously unknown subset of thermosensory cells.

In further support of the importance of TRPA channels in Drosophila thermosensation, a temperature preference screen of P-element insertion mutants isolated the pyrexia mutant, which codes for dTRPA2 [43]. In vitro, temperatures above $40^{\circ} \mathrm{C}$ evoke ionic currents in cells expressing dTRPA2 that primarily conducts potassium ions over sodium, suggesting that thermal activation of the channel does not lead to depolarization but will in fact hyperpolarize the neuron. The channel is expressed in a number of sensory neurons that innervate bristles located around the eyes and on the dorsal part of the thorax and in the proboscis and antennae. Interestingly, dTRPA2 is expressed not only in multidendritic neurons, as is Painless, but also in non-multidendritic neurons that line the epidermis. dTRPA2-specific antibodies detect robust neurite expression but, surprisingly, not in the axonal tips as would be expected for a sensor. The most robust phenotype of dTRPA2-null flies is a remarkable paralysis evoked when the animals are exposed to temperatures above $40^{\circ} \mathrm{C}$. Thus, the cellular localization, high permeability to potassium, and paralytic phenotype to high temperatures suggest that this channel serves to protect flies from high temperature strain [43].

\section{Other thermosensory mechanisms}

The preponderance of evidence suggests that members of the TRPA subfamily mediate thermosensory responses in Drosophila. However, a recent study has uncovered a new potential player in thermosensation, histamine. Hong et al. performed a P-element screen very much like that used to identify the pyrexia mutants [43], and isolated several mutants which exhibit deficits in thermotactic behaviors [45]. The genes identified encode several proteins that serve in histamine signaling, including a subunit of a histamine-

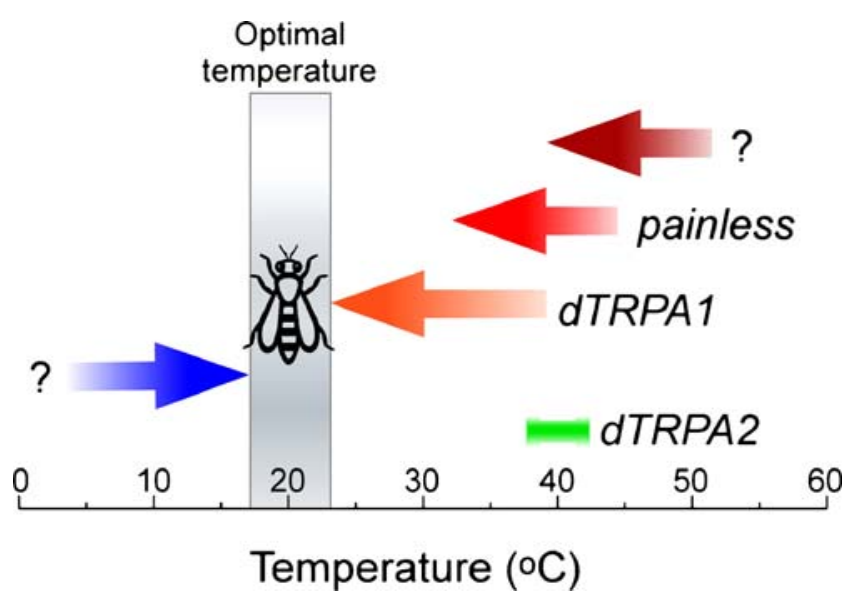

Fig. 2 Drosophila TRP ion channels drive both larvae and adult flies to thermotax towards the optimum growth temperature or provide aversive signals from noxious stimuli. dTRPA1 and an unknown thermosensor drive animals towards the optimum clime, whereas Painless allows them to avoid noxious heat. dTRPA2 provides thermotolerance for temperatures near the noxious range. Aversive responses to high intensity noxious heat $\left(>50^{\circ} \mathrm{C}\right)$ is mediated by an unknown thermosensor 
gated ion channel and histamine decarboxylase. Expression of these proteins is found throughout the central nervous system but not co-expressed with dTRPA1. These mutants display a preference for warmer temperatures near $27^{\circ} \mathrm{C}$, whereas wild type and rescued animals prefer to congregate near $24^{\circ} \mathrm{C}$ [45]. Interestingly, pharmacological antagonists of histamine receptors evoke a similar phenotype as the histaminergic mutants.

From these studies and those previously discussed, a model for Drosophila thermosensation can be posed, which includes at least five separate pathways (Fig. 2). First, type I sensory neurons of the chordotonal organs serve as cold thermoceptors and drive larvae from cold temperatures $\left(\sim 10-18^{\circ} \mathrm{C}\right)$ towards the optimal growth temperature. Second, thermosensory cells expressing dTRPA1 reciprocally drive larvae to thermotax toward the growth temperature from warm temperatures $(\sim 38$ $\left.24^{\circ} \mathrm{C}\right)$. Third, type II multidendritic sensory neurons expressing Painless mediate nocifensive responses to moderately noxious heat greater than $38^{\circ} \mathrm{C}$. Fourth, dTRPA2 provides flies a mechanism to establish thermal tolerance. Last, an as yet unidentified sensory pathway mediates nocifensive response to highly noxious heat $\left(\sim 52^{\circ} \mathrm{C}\right)$ and, like the Painless pathway, evokes an escape response to harmful stimuli. All told, it is clear that TRP ion channels are crucial for at least three of these pathways, and it remains to be seen if other members are involved in determining the remaining thermosensory responses or if other molecular players, such as those involved in histamine signaling, are required for some portions of Drosophila thermosensation.

\section{Vertebrate thermosensory mechanisms}

Although many aspects still remain enigmatic, the relative minimalism of the nematode nervous system was crucial in the discovery of the cast of neuronal players in C. elegans thermosensation. As evidenced in Drosophila, the circumstances are exceedingly more complex in higher organisms. However, the robust molecular tools available in Drosophila have enabled many researchers to begin to unravel the genetic and molecular logic for thermosensation in the fruit fly in a relatively short period of time. However, mammals are neither simplistic in their neural networks nor are the same molecular and genetic approaches available in $C$. elegans and Drosophila practical in vertebrate model systems, such as the mouse. Nonetheless, the last decade has been replete with fundamental and seminal discoveries into the biological processes that mediate temperature sensation in mammals. Remarkably, the key to these great strides was not the advent of a new genetic or cellular manipulation but was in fact due to the properties of plant extracts that have been employed medicinally and in culinary fare for centuries [46].

As the active ingredients in hot chili peppers and mint leaves mimic the distinct psychophysical sensations of hot and cold, respectively, it was reasoned that if the molecular targets of these compounds were identified, these receptor proteins were likely to be involved in mediating the detection of temperature [46]. This hypothesis was first validated when Caterina et al. [25] cloned the capsaicin receptor, TRPV1, from DRG neurons and established that this ion channel is activated by noxious heat in vitro. Subsequently, we identified a cold and menthol receptor, TRPM8, from TG neurons using a similar paradigm, thereby establishing that members of the TRP family of ion channels play an important role in thermosensation [47]. Subsequently, four additional TRP channels have been implicated in temperature sensation both in vitro and in vivo, and their properties, along with TRPV1 and TRPM8, can conceivably account for the entire spectrum of perceived temperatures [48-55] (Fig. 3).

The hot of capsaicin and the cool of menthol

Over a half century ago, Nicolas Jancsó demonstrated that, when applied to the skin, capsaicin produces a robust burning sensation, which is followed by vasodilation and neurogenic inflammation (reviewed in [56]). Furthermore, high doses of capsaicin produce analgesia, referred to as capsaicin desensitization, such that ensuing heat and chemical stimulation are less likely to be perceived [57]. Capsaicin also has central nervous system effects exhibited as a marked fall in body temperature when capsaicin is given systemically. This hypothermic effect is due, in part, to vasodilation and a fall in metabolic activity at cool

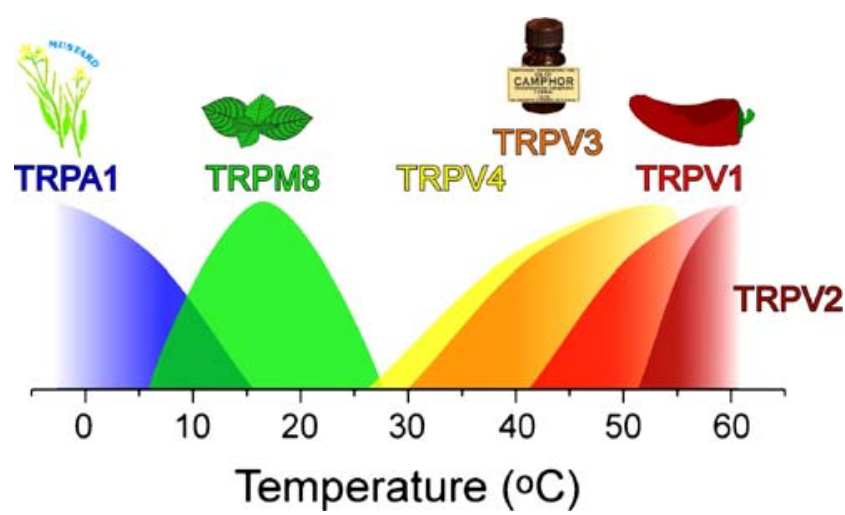

Fig. 3 Mammalian TRP ion channels detect a broad range of temperatures and their in vitro properties predict the thermal zones each channel potentially mediates. Moreover, many of these channels are activated by plant derivatives, which provide distinct sensations of temperature. Mouse models have shown that TRPV1, TRPV3, and TRPV4 are involved in thermosensing in vivo, whereas analyses of cold response in TRPA1-null mice are controversial 
temperatures [56]. However, when given systemically to neonatal rats, capsaicin induces the selective degeneration of small-diameter sensory neurons, leading to reduced vasodilation and the absence of systemic capsaicin-mediated reductions in body temperature [58]. Likewise, as in adults, capsaicin-treated rats are less responsive to stimulation with chemical irritants and noxious heat.

Psychophysically, we perceive the shift between innocuous warmth and noxious heat near $43^{\circ} \mathrm{C}$. Temperatures above this 'moderate' threshold evoke responses in approximately half of rodent primary afferent fibers, whereas a smaller proportion respond at 'high' threshold temperatures above $52^{\circ} \mathrm{C}[59,60]$. The former population is made up by $\mathrm{C}$ - and type II A $\delta$-fibers, whereas the latter are composed of type I A $\delta$-fibers [37]. Interestingly, the majority of heatsensitive fibers with a "moderate" thermal threshold of $\sim 43^{\circ} \mathrm{C}$ are activated by capsaicin, a functional feature of nociceptive sensory neurons [59]. Capsaicin, like noxious heat, depolarizes select subsets of sensory afferents by increasing the permeability to $\mathrm{Na}^{+}$and $\mathrm{Ca}^{2+}$ ions $[59,61-$ 63]. Thus, capsaicin and capsaicin-sensitive afferents mediate many of the elements associated with noxious heat stimulation.

As with capsaicin and the perception of heat, the cooling compound menthol evokes a sensation of cold. Menthol, a cyclic terpene alcohol found in leaves of plants of the Mentha species, is used in a wide range of products, such as confectionary, candy, toothpastes, vapo-rubs, and aromatherapy inhalations [64]. Moderate concentrations of menthol induce a pleasant cool sensation, whereas higher doses can be noxious, causing burning, irritation, and pain [6569]. From seminal studies conducted by Hensel and Zotterman [70] in the 1950s, it came to be appreciated that menthol elicits its "cool" sensation by decreasing the threshold temperature for activation of cold receptors. Indeed, they hypothesized that menthol exerts its actions upon "an enzyme" that is involved in the activation of these nerves [70]. Similar responses are observed in cultured neurons with both menthol and cold evoking rapidly activating, nonselective cation conductances in a temperature-dependent manner [47, 71]. Both menthol- and coldevoked currents also adapt to prolonged stimulation at a rate that is similar to what is observed in primates and humans [72].

In contrast to the definitive thermal thresholds of noxious heat-sensitive nerves, similar distinctions for noxious cold-sensitive fibers are not as easily resolved. In most cases, the perception of cold initiates when the skin is cooled as little as $1^{\circ} \mathrm{C}$ from normal body temperature [73]. In electrophysiological recordings, both $\mathrm{C}$ - and $\mathrm{A} \delta$-cold fibers fire continuously at body temperature with cooling in the range of $30-15^{\circ} \mathrm{C}$ increasing the rate of firing, whereas warmer temperatures decrease firing [73-76]. The percep- tion of cold pain is felt as temperature approach $15^{\circ} \mathrm{C}$ with qualities perceived as burning, aching, or pricking [77]. As described previously, studies into cold-sensitive fibers were inconclusive in defining the biological basis for cold signaling. However, a number of laboratories interested in cold transduction began to use primary cultures of either DRG or TG neurons as in vitro models of sensory afferents. Approximately $10 \%$ respond to cold temperatures, with thresholds for activation below $30^{\circ} \mathrm{C}$, and almost all of these sensory neurons are menthol-sensitive as well [47, 71, $78,79]$. Thus, these in vitro data support the hypotheses of Hensel and Zotterman in that it seemed likely that cold and menthol work through a similar mechanism, leading to the search for their common molecular site of action.

\section{Cloning of the capsaicin and menthol receptors}

In the nematode, the milestone in thermosensory research was the discovery of the requirement of AFD in appropriate temperature response [5]. In vertebrates, the same significance can be placed upon the cloning of the capsaicin receptor, TRPV1, in 1997 [25]. TRPV1, when expressed in heterologous expression systems, produces a large cationic current in response to not only capsaicin but also to noxious heat at a temperature threshold near $43^{\circ} \mathrm{C}$. Additionally, TRPV1 currents are $\mathrm{pH}$-sensitive, demonstrating that the channel functions as a polymodal detector of noxious stimuli in that it is sensitive to heat, capsaicin, and protons $[46,80]$. Hence, the cloning and functional analysis of TRPV1 revealed for the first time how sensory neurons detect "moderate" threshold heat responses at the molecular level. Furthermore, several additional TRPV channels are also activated by warmth and heat, suggesting that thermosensory responses to heat are largely mediated by one class of proteins (see below) [48-50, 52-54].

Similar to the process where a sensor for heat was found with capsaicin, we and others identified a cold sensor on sensory afferents by cloning a menthol receptor, TRPM 8 $[47,51]$. When the channel is expressed in heterologous expression systems, currents are activated by a number of cooling compounds in addition to menthol, such as eucalyptol (the active ingredient in eucalyptus oil) and the super-cooling compound AG-3-5 [47, 81]. Biophysically, TRPM8 has surprisingly similar properties to those recorded in both cultured DRG and TG neurons using similar experimental paradigms [47, 71]. TRPM8 currents are evoked by cold with an activation threshold temperature of $\sim 26^{\circ} \mathrm{C}$, with activity increasing in magnitude down to $8^{\circ} \mathrm{C}$, spanning what are considered both innocuous cool $\left(\sim 30-15^{\circ} \mathrm{C}\right)$ and noxious cold temperatures $\left(<15^{\circ} \mathrm{C}\right)[47$, 51]. TRPM 8 was the first cold-activated ion channel to be identified and established the general role for TRP ion channels in thermosensation. 
Mouse models deficient in temperature sensing

The cloning of TRPV1 and TRPM8 called attention to the essential role of TRP ion channels in temperature sensing in vertebrates. This has been further validated with the identification of several additional TRPs as likely thermosensors, including TRPV2, TRPV3, TRPV4, and, perhaps, TRPA1 [46]. These channels were identified as such based upon either their sequence or structural similarity to TRPV1, expression in sensory afferents, or in vitro biophysical properties [46]. The first of these, TRPV2, is a candidate transducer of high threshold heat responses observed in medium diameter, lightly myelinated type I A $\delta$ fibers that respond to temperatures $>50^{\circ} \mathrm{C}[48,59]$. In vitro, TRPV2-mediated currents are activated at a threshold temperature of $52^{\circ} \mathrm{C}$, and TRPV2 expression in sensory ganglia is suggestive of expression in type I A $\delta$ fibers [48, 82]. However, behavioral responses of TRPV2-null mice have not been reported. Similarly, TRPM8-deficient mice have also not been produced; thus, the putative in vivo roles for these two channels have not been addressed experimentally. In contrast of the other TRP channels implicated in mammalian thermosensation, knockout mice for TRPV1, TRPV3, TRPV4, and TRPA1 have been generated and characterized [41, 83-85].

TRPV1 was the first thermosensor to be critically tested in vivo $[86,87]$. Isolated sensory neurons obtained from TRPV1-null mice do not respond to capsaicin, lack heatgated responses in the moderate threshold range, and have visibly diminished sustained acid-evoked currents in vitro. In vivo, $\mathrm{TRPV}^{-1-}$ mice no longer exhibit nocifensive responses to vanilloids and are impervious to capsaicinmediated hypothermia. Capsaicin also affects urinary function, stimulating bladder afferent neurons, which results in a voiding reflex that is absent in TRPV $1^{-/-}$mice $[88,89]$. Surprisingly, nocifensive behaviors to temperatures in the moderate threshold range $\left(43\right.$ to $\left.48^{\circ} \mathrm{C}\right)$ were similar to wild types, but TRPV1-null mice do exhibit reduced responsiveness to temperatures above $50^{\circ} \mathrm{C}[86$, 87]. More strikingly, TRPV1-null mice fail to develop hypersensitivity, or hyperalgesia, to thermal stimuli after inflammatory peripheral tissue injury $[86,87]$. Inflammation creates a local tissue acidosis, along with the production of several inflammatory mediators that induce thermal and mechanical hyperalgesia [37]. Hypersensitivity to thermal stimuli associated with inflammation are completely absent in TRPV1-null mice, although mechanical hypersensitivity remains intact. Thus, TRPV1-null mice lack essentially all of the physiological and pathological responses associated with capsaicin stimulation and do not develop inflammatory thermal hyperalgesia but are still sensitive to moderately noxious heat.
In vitro, TRPV3 and TRPV4 are activated at temperatures considered warm [49, 50, 52-54]. TRPV4, a functional orthologue of the $C$. elegans TRP channel Osm-9 [90, 91], was first identified as an osmosensitive ion channel and is activated by decreased osmolarity [9294]. However, subsequent studies suggest that TRPV4 is a polymodal receptor, as it can also be triggered at temperatures $>25^{\circ} \mathrm{C}$ and protons $[49,50]$. The channel is expressed in several tissues, including the preoptic/anterior hypothalamus, keratinocytes, and primary sensory neurons, all regions that serve in various aspects of thermosensation and thermoregulation [50, 94, 95]. TRPV3, alternatively, is activated by a number of natural plant products that produce a sensation of warmth, including camphor and the active components of oregano, thyme, and cloves [83, 96]. Remarkably, TRPV3 appears to be exclusively expressed in keratinocytes, and ionic currents are reported to be evoked at threshold temperatures of either 31 or $39^{\circ} \mathrm{C}$ in heterologous cells expressing the channel [52-54]. Thus, these two TRPV channels were hypothesized to mediate the signaling of warm temperatures in ranges below that detected by either TRPV1 or TRPV2.

Indeed, behavioral analyses of TRPV3- and TRPV4-null mice partially bears the above hypothesis out, with some subtle differences in thermosensory responses [83, 84]. When placed upon a thermal gradient $\left(0.9\right.$ to $\left.48.8^{\circ} \mathrm{C}\right)$, TRPV4-null mice prefer warmer temperatures in comparison to their wild type littermates $\left(28.1^{\circ} \mathrm{C}\right.$ for wild type and $32^{\circ} \mathrm{C}$ for $\mathrm{TRPV}^{-/-}$) [84]. Additionally, when given the choice between two innocuously warm temperatures, they are partial for 34 over $30^{\circ} \mathrm{C}$, a phenotype not observed in wild type mice. However, when asked to choose between 34 and $36^{\circ} \mathrm{C}$, both wild type and TRPV4 nulls show a strong preference for the cooler temperature. This behavioral phenotype suggests that TRPV4 activation drives mice towards temperatures near $30^{\circ} \mathrm{C}$, but that mice lacking this channel still retain the ability to avoid higher temperatures [84]. Surprisingly, TRPV4-null mice also present with a prolonged withdrawal latency to noxious temperatures (near $47^{\circ} \mathrm{C}$ ) in a tail water-immersion assay, suggesting that the channel mediates some aspects of acute avoidance of noxious heat in addition to thermotactic behaviors [84].

When given the choice between floor plate zones held at either room temperature or $35^{\circ} \mathrm{C}$, wild type mice spend $>90 \%$ of their time in the warmer zone [83]. However, mice lacking TRPV3 fail to migrate to $35^{\circ} \mathrm{C}$ when given this choice but strongly avoid colder temperatures $\left(15^{\circ} \mathrm{C}\right)$ versus room temperature, similar to wild type mice [83]. In a temperature gradient assay similar to that used to test TRPV4 nulls $\left(15\right.$ to $55^{\circ} \mathrm{C}$ ), wild type mice, after $30 \mathrm{~min}$ of exploring the experimental chamber, spend the majority of the time between 30 and $38^{\circ} \mathrm{C}$, whereas TRPV 3 nulls display no significant preference for this restricted zone 
during this timeframe [83]. Interestingly, this inability to identify the preferred thermal zone is transitory, as $\mathrm{TRPV}^{-1-}$ mice will eventually migrate to $35^{\circ} \mathrm{C}$ after approximately $1 \mathrm{~h}$ in the chamber. Thus, TRPV3 appears to be partially necessary in vivo for the ability to thermotax towards warmth, but mice lacking this channel will eventually acquire normal thermal preference with time using alternative mechanisms. Additionally, similar to TRPV4-null mice, there is a subtle behavioral deficiency in high threshold noxious heat responses $\left(>50^{\circ} \mathrm{C}\right)$ in $\mathrm{TRPV}^{-1-}$ mice, a phenotype similar to TRPV1 nulls [87]. Thus, mice deficient in any of the three heat sensitive TRPV channels display similar behavioral phenotypes in their acute nocifensive responses to extreme heat but exhibit no behavioral deficits in responses to moderate noxious heat. Moreover, as both TRPV3 and TRPV4 are expressed in keratinocytes, the former exclusively, it is unclear how thermal activation of these channels in nonneuronal cells is transmitted to sensory neurons to communicate thermal stimuli.

The thermosensitive TRP ion channels described above perform functionally in mediating heat both in vivo and in vitro. However, a non-TRP-related mouse model has been described in which thermosensation is impaired, namely, mice deficient in the ionotropic purinergic receptor $\mathrm{P} 2 \mathrm{X}_{3}$ [97]. This is an ATP-gated ion channel that is expressed in a subpopulation of small-diameter nociceptive neurons. ATP released upon tissue damage produces a sensation of pain, and mice null in $\mathrm{P}_{2} \mathrm{X}_{3}$ lack rapidly desensitizing ATP-gated cation currents. However, an unexpected observation in $\mathrm{P} 2 \mathrm{X}_{3}$-null mice is that, in electrophysiological recordings from spinal cord wide dynamic range neurons, they are unable to code the intensity of innocuous warm stimuli but retain sensitivity to noxious heat [98]. Thus, these results suggest that $\mathrm{P} 2 \mathrm{X}_{3}$, although it has not been reported to be activated by warm temperatures in vitro, has a role in warm thermosensation in vivo. However, behavioral studies of $\mathrm{P}_{2} \mathrm{X}_{3}$-null mice subsequently found that these mice unexpectedly exhibit enhanced avoidance of both hot and cold temperatures when studied in the linear thermal gradient paradigm [99]. Moreover, they also show signs of enhanced avoidance in the water-immersion tail flick assay to both hot and cold temperatures generally considered noxious. Thus, whereas in vitro recordings suggest that warm thermal signaling is absent in $\mathrm{P} 2 \mathrm{X}_{3}$-nulls, behavioral experiments have shown that $\mathrm{P}_{2} \mathrm{X}_{3}{ }^{-/}$-deficient mice are unexpectedly better able to avoid unpleasant temperatures than wild types.

Whereas the in vitro and in vivo discrepancies observed with $\mathrm{P} 2 \mathrm{X}_{3}$-null mice have perplexed many in the thermosensory field, two independent reports on TRPA1-null mice have further complicated an already confusing story [72, 100]. TRPA1 was first reported by Story et al. [55] to be activated in vitro by cold temperatures near that considered noxious $\left(<17^{\circ} \mathrm{C}\right)$. However, the hypothesis that TRPA1 mediates perceptual responses to noxious cold was contradicted by at least two laboratories that could not reproduce cold activation of the channel in vitro [40, 101]. Furthermore, TRPA1 was shown to be a receptor for several pungent compounds, including the active ingredients in wasabi, cinnamon, and uncooked garlic [40, 102-104]. Several laboratories have examined the correlation between cold responses and these agonists, with mixed and inconclusive results [40, 72, 102-105]. Thus, a chilly controversy arose regarding the involvement of TRPA1 in thermosensation, one that would presumably be resolved by the study of TRPA1-null mice.

Unfortunately, this turned out not to be the case. Working independently, the laboratories of David Julius and David Corey generated TRPA1-null mice and tested their sensitivity to cold $[41,85]$. In a remarkable similarity to the discrepancies found with TRPA1 responses to cold in vitro, one group observed no cold sensation deficits in the knockout mice, whereas the second group did. Bautista et al. [41] found that the percentage of cold-sensitive sensory neurons in culture, number of nocifensive responses to acetone-evoked cooling, paw-withdrawal latencies, and induction of shivering in a cold-plate paradigm (20 to $-10^{\circ} \mathrm{C}$ ) were indistinguishable in wild type and TRPA $1^{-/-}$ mice. In the contrary, Kwan et al. [85] did report a decrease number of paw lifts when TRPA $1^{-/}$mice were placed upon a surface cooled to $0^{\circ} \mathrm{C}$, as well as in the duration of paw shakes during acetone evaporative cooling. However, this significant difference in thermal sensitivity was only observed in female mice and not in males. When aggregate data obtained from male and female mice are considered, the differences in cold-evoked responses are significantly dissimilar. Conversely, when the data are analyzed by gender, female TRPA $1^{-1-}$ mice exhibit markedly reduced cold sensitivity, whereas males do not (see supplemental Fig. S1 of Kwan et al. [85]). Gender differences in pain sensitivity are well established [106], but the underlying mechanisms for the observed cold sensation differences between male and female mice deficient in TRPA1 in the Kwan et al. study remains enigmatic. Furthermore, it is difficult to compare the results of these behavioral studies of TRPA $1^{-/}$mice, as they were performed in subtly different ways (i.e. measurements of paw-withdrawal latency versus duration) [41, 107].

\section{Other thermosensory processes}

Besides the known thermosensitive TRP ion channels, several additional thermosensory mechanisms have been suggested through in vitro studies. It is a biochemical axiom that cold temperatures hamper protein function, and 
this inhibitory property of cold has been suggested to be a mechanism for neuronal depolarization. A number of studies have suggested that cold inhibition of background $\mathrm{K}^{+}$conductances or the $\mathrm{Na}^{+} / \mathrm{K}^{+}$-ATPase leads to membrane depolarization of cold-sensitive afferents [78, 108110]. In the former example, the $\mathrm{K}^{+}$-channel TREK-1 is strongly inhibited by cooling in vitro and expressed very highly in sensory neurons [111]. Thus, it has been proposed that thermosensory neurons depolarize by coldevoked inhibition of TREK-1 [111]. However, similar to the hypothesized role of $\mathrm{P}_{2} \mathrm{X}_{3}$ based upon the in vitro data, TREK-1-null mice do not exhibit any significant differences in response to cold in isolated skin-saphenous nerve preparations [112]. Indeed, C-fibers recorded from TREK $-1^{-1-}$ mice are more sensitive to heat than wild types, firing more action potentials and have a lowered firing threshold in response to noxious heat. This observation is consistent with cellular localization of this $\mathrm{K}^{+}$channel, which is extensively co-localized with TRPV1 [112]. Thus, TREK-1 likely plays an important role in membrane excitability in sensory afferents, and its absence makes nociceptors more readily depolarized.

Members of the degenerin family of epithelial sodium channels (DEG/ENaC) are involved in many aspects of sensory signaling, including mechanosensory responses in the touch cells of $C$. elegans, responses in mammalian mechanoreceptors, salt and sour taste in mice, and proton responses in sensory afferents [113-116]. In regard to thermosensory signaling, in vitro recordings find that many of these channels are potentiated by cold temperatures [117]. The constitutively active epithelial ENaC channel is markedly potentiated by cold temperatures with a half-maximal response near $25^{\circ} \mathrm{C}$. Three other channels of this family, which are acid-gated, including the DRGspecific DRASIC, were potentiated by cooling by slowing channel inactivation [117]. However, thermosensation deficits in mice null for these channels have yet to be reported $[118,119]$.

\section{Conclusions}

Although tremendous strides have been made in our understanding of the neurons and molecules involved in thermosensation, many of the processes used by various organisms to detect thermal change remain enigmatic. In the nematode, two key thermosensor neurons have yet to be identified, namely, the sensory neuron presynaptic to AIZ, and the nociceptor(s) that is(are) responsible for the response to noxious heat. The identification of these neurons will undoubtedly lead to the discovery of new molecular players in C. elegans thermosensation. In the fruit fly, it is still not clear if Painless is an obligatory detector of thermal and mechanical stimuli or if it is a crucial player downstream of an unknown "sensor" in the signal transduction cascade of moderately noxious heat and force. Moreover, the identities of the molecules that mediate the response to high threshold noxious heat in Drosophila larvae remain unclear. In mammalian systems, the roles of TRPV2 and TRPM8 in thermosensation still need to be evaluated in vivo, as well as how TRPV3 or TRPV4-mediated changes in keratinocyte activity are transduced to the central nervous system. These are only a few examples of the outstanding questions in the field and many others can be posed. However, if the pace of research that has led to the seminal and exciting discoveries described in this paper continues, answers to these and other fundamental questions will undoubtedly arise shortly.

Acknowledgment This work was supported by a grant from NIH/ NINDS (to D.D.M.).

\section{References}

1. Mori I (1999) Genetics of chemotaxis and thermotaxis in the nematode Caenorhabditis elegans. Annu Rev Genet 33:399-422

2. Bono Md, Villu Maricq A (2005) Neuronal substrates of complex behaviors in C. elegans. Annu Rev Neurosci 28(1):451-501

3. Hedgecock EM, Russell RL (1975) Normal and mutant thermotaxis in the nematode Caenorhabditis elegans. Proc Natl Acad Sci USA 72(10):4061-4065

4. Mohri A, Kodama E, Kimura KD, Koike M, Mizuno T, Mori I (2005) Genetic control of temperature preference in the nematode Caenorhabditis elegans. Genetics 169(3):1437-1450

5. Mori I, Ohshima Y (1995) Neural regulation of thermotaxis in Caenorhabditis elegans. Nature 376(6538):344-348

6. White JG, Southgate E, Thomson JN, Brenner S (1986) The structure of the nervous system of the nematode Caenorhabditis elegans. Philos Trans R Soc Lond B314:1-340

7. Kimura KD, Miyawaki A, Matsumoto K, Mori I (2004) The $C$. elegans thermosensory neuron AFD responds to warming. Curr Biol 14(14):1291-1295

8. Clark DA, Biron D, Sengupta P, Samuel AD (2006) The AFD sensory neurons encode multiple functions underlying thermotactic behavior in Caenorhabditis elegans. J Neurosci 26 (28):7444-7451

9. Coburn CM, Bargmann CI (1996) A putative cyclic nucleotidegated channel is required for sensory development and function in C. elegans. Neuron 17(4):695-706

10. Komatsu H, Mori I, Rhee JS, Akaike N, Ohshima Y (1996) Mutations in a cyclic nucleotide-gated channel lead to abnormal thermosensation and chemosensation in C. elegans. Neuron 17 (4):707-718

11. Komatsu H, Jin Y-H, L'Etoile N, Mori I, Bargmann CI, Akaike $\mathrm{N}$ et al (1999) Functional reconstitution of a heteromeric cyclic nucleotide-gated channel of Caenorhabditis elegans in cultured cells. Brain Res 821(1):160-168

12. Inada H, Ito H, Satterlee J, Sengupta P, Matsumoto K, Mori I (2006) Identification of guanylyl cyclases that function in thermosensory neurons of Caenorhabditis elegans. Genetics 172(4):2239-2252

13. Satterlee JS, Sasakura H, Kuhara A, Berkeley M, Mori I, Sengupta $\mathrm{P}$ (2001) Specification of thermosensory neuron fate in 
C. elegans requires $\mathrm{ttx}-1$, a homolog of otd/Otx. Neuron 31 (6):943-956

14. Perkins LA, Hedgecock EM, Thomson JN, Culotti JG (1986) Mutant sensory cilia in the nematode Caenorhabditis elegans. Dev Biol 117(2):456-487

15. Lanjuin A, VanHoven MK, Bargmann CI, Thompson JK, Sengupta P (2003) Otx/otd homeobox genes specify distinct sensory neuron identities in C. elegans. Dev Cell 5(4):621-633

16. Hobert O, Mori I, Yamashita Y, Honda H, Ohshima Y, Liu Y et al (1997) Regulation of interneuron function in the C. elegans thermoregulatory pathway by the ttx-3 LIM homeobox gene. Neuron 19(2):345-357

17. Hobert O, Ruvkun G (1998) A common theme for LIM homeobox gene function across phylogeny? Biol Bull 195 (3):377-380

18. Cassata G, Kagoshima H, Andachi Y, Kohara Y, Durrenberger MB, Hall DH et al (2000) The LIM homeobox gene ceh-14 confers thermosensory function to the AFD neurons in Caenorhabditis elegans. Neuron 25(3):587-597

19. Satterlee JS, Ryu WS, Sengupta P (2004) The CMK-1 CaMKI and the TAX-4 cyclic nucleotide-gated channel regulate thermosensory neuron gene expression and function in C. elegans. Curr Biol 14(1):62-68

20. Dusenbery DB, Sheridan RE, Russell RL (1975) Chemotaxisdefective mutants of the nematode Caenorhabditis elegans. Genetics 80(2):297-309

21. Kuhara A, Inada H, Katsura I, Mori I (2002) Negative regulation and gain control of sensory neurons by the $C$. elegans calcineurin TAX-6. Neuron 33(5):751-763

22. Kuhara A, Mori I (2006) Molecular physiology of the neural circuit for calcineurin-dependent associative learning in Caenorhabditis elegans. J Neurosci 26(37):9355-9364

23. Tobin DM, Bargmann CI (2004) Invertebrate nociception: behaviors, neurons and molecules. J Neurobiol 61(1):161-174

24. Wittenburg N, Baumeister R (1999) Thermal avoidance in Caenorhabditis elegans: an approach to the study of nociception. Proc Natl Acad Sci USA 96(18):10477-10482

25. Caterina MJ, Schumacher MA, Tominaga M, Rosen TA, Levine JD, Julius D (1997) The capsaicin receptor: a heat-activated ion channel in the pain pathway. Nature 389(6653):816-824

26. Tobin DM, Madsen DM, Kahn-Kirby A, Peckol EL, Moulder G, Barstead R et al (2002) Combinatorial expression of TRPV channel proteins defines their sensory functions and subcellular localization in C. elegans neurons. Neuron 35(2):307-318

27. Amrein H, Thorne N (2005) Gustatory perception and behavior in drosophila melanogaster. Curr Biol 15(17):R673-R684

28. Scott K (2005) Taste recognition: food for thought. Neuron 48 (3):455-464

29. Montell C (2005) Drosophila TRP channels. Pflugers Arch 451 (1):19-28

30. Sayeed O, Benzer S (1996) Behavioral genetics of thermosensation and hygrosensation in Drosophila. Proc Natl Acad Sci USA 93(12):6079-6084

31. Liu L, Yermolaieva O, Johnson WA, Abboud FM, Welsh MJ (2003) Identification and function of thermosensory neurons in Drosophila larvae. Nat Neurosci 6(3):267-273

32. Rosenzweig M, Brennan KM, Tayler TD, Phelps PO, Patapoutian A, Garrity PA (2005) The Drosophila ortholog of vertebrate TRPA1 regulates thermotaxis. Genes Dev 19(4):419-424

33. Tracey WD Jr, Wilson RI, Laurent G, Benzer S (2003) painless, a Drosophila gene essential for nociception. Cell 113(2):261-273

34. Kernan M, Cowan D, Zuker C (1994) Genetic dissection of mechanosensory transduction: mechanoreception-defective mutations of Drosophila. Neuron 12(6):1195-1206

35. Zars T (2001) Two thermosensors in Drosophila have different behavioral functions. J Comp Physiol A 187(3):235-242
36. Gillespie PG, Walker RG (2001) Molecular basis of mechanosensory transduction. Nature 413(6852):194-202

37. Julius D, Basbaum AI (2001) Molecular mechanisms of nociception. Nature 413(6852):203-210

38. Al-Anzi B, Tracey WD Jr, Benzer S (2006) Response of Drosophila to wasabi is mediated by painless, the fly homolog of mammalian TRPA1/ANKTM1. Curr Biol 16(10):1034-1040

39. Wang Z, Singhvi A, Kong P, Scott K (2004) Taste representations in the Drosophila brain. Cell 117(7):981-991

40. Jordt SE, Bautista DM, Chuang HH, McKemy DD, Zygmunt PM, Hogestatt ED et al (2004) Mustard oils and cannabinoids excite sensory nerve fibres through the TRP channel ANKTM1. Nature 427(6971):260-265

41. Bautista DM, Jordt SE, Nikai T, Tsuruda PR, Read AJ, Poblete $J$ et al (2006) TRPA1 mediates the inflammatory actions of environmental irritants and proalgesic agents. Cell 124 (6):1269-1282

42. Montell C (2005) The TRP superfamily of cation channels. Sci STKE 272:re3

43. Lee Y, Lee Y, Lee J, Bang S, Hyun S, Kang J et al (2005) Pyrexia is a new thermal transient receptor potential channel endowing tolerance to high temperatures in Drosophila melanogaster. Nat Genet 37(3):305-310

44. Viswanath V, Story GM, Peier AM, Petrus MJ, Lee VM, Hwang SW et al (2003) Opposite thermosensor in fruitfly and mouse. Nature 423(6942):822-823

45. Hong S-T, Bang S, Paik D, Kang J, Hwang S, Jeon K et al (2006) Histamine and its receptors modulate temperaturepreference behaviors in Drosophila. J Neurosci 26(27): $7245-7256$

46. Jordt SE, McKemy DD, Julius D (2003) Lessons from peppers and peppermint: the molecular logic of thermosensation. Curr Opin Neurobiol 13(4):487-492

47. McKemy DD, Neuhausser WM, Julius D (2002) Identification of a cold receptor reveals a general role for TRP channels in thermosensation. Nature 416(6876):52-58

48. Caterina MJ, Rosen TA, Tominaga M, Brake AJ, Julius D (1999) A capsaicin-receptor homologue with a high threshold for noxious heat. Nature 398(6726):436-441

49. Watanabe H, Vriens J, Suh SH, Benham CD, Droogmans G, Nilius B (2002) Heat-evoked activation of TRPV4 channels in a HEK293 cell expression system and in native mouse aorta endothelial cells. J Biol Chem 277(49):47044-47051

50. Guler AD, Lee H, Iida T, Shimizu I, Tominaga M, Caterina M (2002) Heat-evoked activation of the ion channel, TRPV4. J Neurosci 22(15):6408-6414

51. Peier AM, Moqrich A, Hergarden AC, Reeve AJ, Andersson DA, Story GM et al (2002) A TRP channel that senses cold stimuli and menthol. Cell 108(5):705-715

52. Smith GD, Gunthorpe MJ, Kelsell RE, Hayes PD, Reilly P, Facer $P$ et al (2002) TRPV3 is a temperature-sensitive vanilloid receptor-like protein. Nature 418(6894):186-190

53. Xu H, Ramsey IS, Kotecha SA, Moran MM, Chong JA, Lawson $\mathrm{D}$ et al (2002) TRPV3 is a calcium-permeable temperaturesensitive cation channel. Nature 418(6894):181-186

54. Peier AM, Reeve AJ, Andersson DA, Moqrich A, Earley TJ, Hergarden AC, et al (2002) A heat-sensitive TRP channel expressed in keratinocytes. Science 296(5575):2046-2049

55. Story GM, Peier AM, Reeve AJ, Eid SR, Mosbacher J, Hricik TR et al (2003) ANKTM1, a TRP-like channel expressed in nociceptive neurons, is activated by cold temperatures. Cell 112 (6):819-829

56. Szolcsanyi J (2004) Forty years in capsaicin research for sensory pharmacology and physiology. Neuropeptides 38(6):377-384

57. Jancso N, Jancso-Gabor A, Szolcsanyi J (1967) Direct evidence for neurogenic inflammation and its prevention by denervation 
and by pretreatment with capsaicin. Br J Pharmacol Chemother 31(1):138-151

58. Jancso G, Kiraly E, Jancso-Gabor A (1977) Pharmacologically induced selective degeneration of chemosensitive primary sensory neurones. Nature 270(5639):741-743

59. Nagy I, Rang H (1999) Noxious heat activates all capsaicinsensitive and also a sub-population of capsaicin-insensitive dorsal root ganglion neurons. Neuroscience 88(4):995-997

60. Treede RD, Meyer RA, Raja SN, Campbell JN (1995) Evidence for two different heat transduction mechanisms in nociceptive primary afferents innervating monkey skin. J Physiol 483(Pt 3): 747-758

61. Bevan S, Szolcsanyi J (1990) Sensory neuron-specific actions of capsaicin: mechanisms and applications. Trends Pharmacol Sci 11(8):330-333

62. Marsh SJ, Stansfeld CE, Brown DA, Davey R, McCarthy D (1987) The mechanism of action of capsaicin on sensory C-type neurons and their axons in vitro. Neuroscience 23(1):275-289

63. Nagy I, Rang HP (1999) Similarities and differences between the responses of rat sensory neurons to noxious heat and capsaicin. J Neurosci 19(24):10647-10655

64. Eccles R (2000) Role of cold receptors and menthol in thirst, the drive to breathe and arousal. Appetite 34(1):29-35

65. Cliff MA, Green BG (1994) Sensory irritation and coolness produced by menthol: evidence for selective desensitization of irritation. Physiol Behav 56(5):1021-1029

66. Eccles R (1994) Menthol and related cooling compounds. J Pharm Pharmacol 46(8):618-630

67. Green BG (1992) The sensory effects of 1-menthol on human skin. Somatosens Motor Res 9(3):235-244

68. Wasner G, Schattschneider J, Binder A, Baron R (2004) Topical menthol - a human model for cold pain by activation and sensitization of C nociceptors. Brain 127(Pt 5):1159-1171

69. Green BG, Schoen KL (2007) Thermal and nociceptive sensations from menthol and their suppression by dynamic contact. Behav Brain Res 176(2):284-91. Epub 2006, November 7

70. Hensel H, Zotterman Y (1951) The effect of menthol on the thermoreceptors. Acta Physiol Scand 24:27-34

71. Reid G, Flonta ML (2001) Physiology. Cold current in thermoreceptive neurons. Nature 413(6855):480

72. Reid G (2005) ThermoTRP channels and cold sensing: what are they really up to? Pflugers Arch 451(1):250-263

73. Campero M, Serra J, Bostock H, Ochoa JL (2001) Slowly conducting afferents activated by innocuous low temperature in human skin. J Physiol 535(Pt 3):855-865

74. LaMotte RH, Thalhammer JG (1982) Response properties of high-threshold cutaneous cold receptors in the primate. Brain Res 244(2):279-287

75. Dubner R, Sumino R, Wood WI (1975) A peripheral “cold” fiber population responsive to innocuous and noxious thermal stimuli applied to monkey's face. J Neurophysiol 38(6):1373-1389

76. Christensen BN, Perl ER (1970) Spinal neurons specifically excited by noxious or thermal stimuli: marginal zone of the dorsal horn. J Neurophysiol 33(2):293-307

77. Morin C, Bushnell MC (1998) Temporal and qualitative properties of cold pain and heat pain: a psychophysical study. Pain 74(1):67-73

78. Viana F, de la Pena E, Belmonte C (2002) Specificity of cold thermotransduction is determined by differential ionic channel expression. Nat Neurosci 5(3):254-260

79. Suto K, Gotoh H (1999) Calcium signaling in cold cells studied in cultured dorsal root ganglion neurons. Neuroscience 92 (3):1131-1135

80. Tominaga M, Caterina MJ, Malmberg AB, Rosen TA, Gilbert H, Skinner K et al (1998) The cloned capsaicin receptor integrates multiple pain-producing stimuli. Neuron 21(3):531-543
81. Wei ET, Seid DA (1983) AG-3-5: a chemical producing sensations of cold. J Pharm Pharmacol 35(2):110-112

82. Ahluwalia J, Rang H, Nagy I (2002) The putative role of vanilloid receptor-like protein-1 in mediating high threshold noxious heat-sensitivity in rat cultured primary sensory neurons. Eur J Neurosci 16(8):1483-1489

83. Moqrich A, Hwang SW, Earley TJ, Petrus MJ, Murray AN, Spencer KS et al (2005) Impaired thermosensation in mice lacking TRPV3, a heat and camphor sensor in the skin. Science 307(5714):1468-1472

84. Lee H, Iida T, Mizuno A, Suzuki M, Caterina MJ (2005) Altered thermal selection behavior in mice lacking transient receptor potential vanilloid 4. J Neurosci 25(5):1304-1310

85. Kwan KY, Allchorne AJ, Vollrath MA, Christensen AP, Zhang DS, Woolf CJ et al (2006) TRPA1 contributes to cold, mechanical, and chemical nociception but is not essential for hair-cell transduction. Neuron 50(2):277-289

86. Davis JB, Gray J, Gunthorpe MJ, Hatcher JP, Davey PT, Overend P et al (2000) Vanilloid receptor-1 is essential for inflammatory thermal hyperalgesia. Nature 405(6783):183-187

87. Caterina MJ, Leffler A, Malmberg AB, Martin WJ, Trafton J, Petersen-Zeitz KR et al (2000) Impaired nociception and pain sensation in mice lacking the capsaicin receptor. Science 288 (5464):306-313

88. Birder LA, Kanai AJ, de Groat WC, Kiss S, Nealen ML, Burke NE et al (2001) Vanilloid receptor expression suggests a sensory role for urinary bladder epithelial cells. Proc Natl Acad Sci USA 98(23):13396-13401

89. Birder LA, Nakamura Y, Kiss S, Nealen ML, Barrick S, Kanai AJ et al (2002) Altered urinary bladder function in mice lacking the vanilloid receptor TRPV1. Nat Neurosci 5(9):856-860

90. Liedtke W, Tobin DM, Bargmann CI, Friedman JM (2003) Mammalian TRPV4 (VR-OAC) directs behavioral responses to osmotic and mechanical stimuli in Caenorhabditis elegans. Proc Natl Acad Sci USA 100(Suppl 2):14531-14536

91. Mutai H, Heller S (2003) Vertebrate and invertebrate TRPV-like mechanoreceptors. Cell Calcium 33(5-6):471-478

92. Strotmann R, Harteneck C, Nunnenmacher K, Schultz G, Plant TD (2000) OTRPC4, a nonselective cation channel that confers sensitivity to extracellular osmolarity. Nat Cell Biol 2(10):695702

93. Wissenbach U, Bodding M, Freichel M, Flockerzi V (2000) Trp12, a novel Trp related protein from kidney. FEBS Lett 485 (2-3):127-134

94. Liedtke W, Choe Y, Marti-Renom MA, Bell AM, Denis CS, Sali A et al (2000) Vanilloid receptor-related osmotically activated channel (VR-OAC), a candidate vertebrate osmoreceptor. Cell 103(3):525-535

95. Alessandri-Haber N, Yeh JJ, Boyd AE, Parada CA, Chen X, Reichling DB et al (2003) Hypotonicity induces TRPV4mediated nociception in rat. Neuron 39(3):497-511

96. Xu H, Delling M, Jun JC, Clapham DE (2006) Oregano, thyme and clove-derived flavors and skin sensitizers activate specific TRP channels. Nat Neurosci 9(5):628-635

97. Chen CC, Akopian AN, Sivilotti L, Colquhoun D, Burnstock G, Wood JN (1995) A P2X purinoceptor expressed by a subset of sensory neurons. Nature 377(6548):428-431

98. Souslova V, Cesare P, Ding Y, Akopian AN, Stanfa L, Suzuki R et al (2000) Warm-coding deficits and aberrant inflammatory pain in mice lacking P2X3 receptors. Nature 407(6807):1015-1017

99. Shimizu I, Iida T, Guan Y, Zhao C, Raja SN, Jarvis MF et al (2005) Enhanced thermal avoidance in mice lacking the ATP receptor P2X3. Pain 116(1-2):96-108

100. McKemy DD (2005) How cold is it? TRPM8 and TRPA1 in the molecular logic of cold sensation. Mol Pain 1(1):16 
101. Nagata K, Duggan A, Kumar G, Garcia-Anoveros J (2005) Nociceptor and hair cell transducer properties of TRPA1, a channel for pain and hearing. J Neurosci 25(16):4052-4061

102. Bandell M, Story GM, Hwang SW, Viswanath V, Eid SR, Petrus MJ et al (2004) Noxious cold ion channel TRPA1 is activated by pungent compounds and bradykinin. Neuron 41(6):849-857

103. Bautista DM, Movahed P, Hinman A, Axelsson HE, Sterner O, Hogestatt ED et al (2005) Pungent products from garlic activate the sensory ion channel TRPA1. Proc Natl Acad Sci USA 102 (34):12248-12252

104. Macpherson LJ, Geierstanger BH, Viswanath V, Bandell M, Eid SR, Hwang S et al (2005) The pungency of garlic: activation of TRPA1 and TRPV1 in response to allicin. Curr Biol 15(10):929-934

105. Namer B, Seifert F, Handwerker HO, Maihofner C (2005) TRPA1 and TRPM8 activation in humans: effects of cinnamaldehyde and menthol. Neuroreport 16(9):955-959

106. Wiesenfeld-Hallin Z (2005) Sex differences in pain perception. Gend Med 2(3):137-145

107. Kwan KY, Allchorne AJ, Vollrath MA, Christensen AP, Zhang D-S, Woolf CJ et al (2006) TRPA1 contributes to cold, mechanical, and chemical nociception but is not essential for hair-cell transduction. Neuron 50(2):277-289

108. Pierau FK, Torrey P, Carpenter D (1975) Effect of ouabain and potassium-free solution on mammalian thermosensitive afferents in vitro. Pflugers Arch 359(4):349-356

109. Pierau FK, Torrey P, Carpenter DO (1974) Mammalian cold receptor afferents: role of an electrogenic sodium pump in sensory transduction. Brain Res 73(1):156-160
110. Reid G, Flonta M (2001) Cold transduction by inhibition of a background potassium conductance in rat primary sensory neurones. Neurosci Lett 297(3):171-174

111. Maingret F, Lauritzen I, Patel AJ, Heurteaux C, Reyes R, Lesage $F$ et al (2000) TREK-1 is a heat-activated background $\mathrm{K}(+)$ channel. EMBO J 19(11):2483-2491

112. Alloui A, Zimmermann K, Mamet J, Duprat F, Noel J, Chemin J et al (2006) TREK-1, a K+ channel involved in polymodal pain perception. EMBO J 25(11):2368-2376

113. Huang M, Chalfie M (1994) Gene interactions affecting mechanosensory transduction in Caenorhabditis elegans. Nature 367(6462):467-470

114. Goodman MB, Ernstrom GG, Chelur DS, O’Hagan R, Yao CA, Chalfie M (2002) MEC-2 regulates C. elegans DEG/ENaC channels needed for mechanosensation. Nature 415(6875):1039-1042

115. Ernstrom GG, Chalfie M (2002) Genetics of sensory mechanotransduction. Ann Rev Genet 36(1):411-453

116. Waldmann R, Champigny G, Bassilana F, Heurteaux C, Lazdunski M (1997) A proton-gated cation channel involved in acid-sensing. Nature 386(6621):173-177

117. Askwith CC, Benson CJ, Welsh MJ, Snyder PM (2001) DEG/ $\mathrm{ENaC}$ ion channels involved in sensory transduction are modulated by cold temperature. Proc Natl Acad Sci USA 98(11):6459-6463

118. Price MP, Mcllwrath SL, Xie J, Cheng C, Qiao J, Tarr DE et al (2001) The DRASIC cation channel contributes to the detection of cutaneous touch and acid stimuli in mice. Neuron 32(6):1071-1083

119. Krishtal O (2003) The ASICs: Signaling molecules? Modulators? Trends Neurosci 26(9):477-483 